\title{
Whose responsibility is it to address the needs of persons with mental health problems? Development of a scale to assess how stakeholders distribute responsibilities across geo-cultural contexts
}

Srividya lyer ( $\sim$ srividya.iyer@mcgill.ca )

Douglas Hospital Centre: Institut universitaire en sante mentale Douglas https://orcid.org/0000-00015367-9086

\section{Megan Pope}

McGill University Department of Psychiatry

\section{Aarati Taksal}

Douglas Mental Health University Institute: Institut universitaire en sante mentale Douglas

\section{Greeshma Mohan}

Schizophrenia Research Foundation

\section{Thara Rangaswamy}

Schizophrenia Research Foundation

\section{Heleen Loohuis}

Douglas Mental Health University Institute: Institut universitaire en sante mentale Douglas

\section{Jai Shah}

McGill University Department of Psychiatry

\section{Ridha Joober}

Douglas Hospital Centre: Institut universitaire en sante mentale Douglas

\section{Norbert Schmitz}

Douglas Mental Health University Institute: Institut universitaire en sante mentale Douglas

Padmavati Ramachandran

Schizophrenia Research Foundation

\section{Ashok Malla}

McGill University Department of Psychiatry

\section{Research}

Keywords: responsibility, mental disorders, psychotic disorders, culture, stakeholder participation, assessment tool 
DOl: https://doi.org/10.21203/rs.3.rs-388384/v1

License: (c) (1) This work is licensed under a Creative Commons Attribution 4.0 International License. Read Full License 


\section{Abstract \\ Background}

Individuals with mental health problems have multiple, often inadequately met needs. Responsibility for meeting these needs frequently falls to patients, their families/caregivers, and governments. Little is known about stakeholders' views of who should be responsible for these needs and there are no measures to assess this construct. This study's objectives were to present the newly designed Whose Responsibility Scale (WRS), which assesses how stakeholders apportion responsibility to persons with mental health problems, their families, and the government for addressing various needs of persons with mental health problems, and to report its psychometric properties.

\section{Methods}

The 22-item WRS asks respondents to assign relative responsibility to the government vis-à-vis persons with mental health problems, government vis-à-vis families, and families vis-à-vis persons with mental health problems for seven support needs. The items were modelled on a World Values Survey item comparing the government's and people's responsibility for ensuring that everyone is provided for. We administered English, Tamil, and French versions to 57 patients, 60 family members, and 27 clinicians at two early psychosis programs in Chennai, India, and Montreal, Canada, evaluating test-retest reliability, internal consistency, and ease of use.

\section{Results}

Test-retest reliability (intra-class correlation coefficients) ranged from excellent to good across stakeholders (patients, families, and clinicians); settings (Montreal and Chennai), and languages (English, French, and Tamil). Internal consistency estimates (Cronbach's alphas) ranged from acceptable to excellent. The WRS scored average on ease of comprehension and completion. Scores were spread across the 1-10 range, suggesting that the scale captured variations in views on how responsibility for meeting needs should be distributed. On select items, scores at one end of the scale were never endorsed, but these reflected expected views about specific needs (e.g., Chennai patients never endorsed patients as being substantially more responsible for housing needs than families).

\section{Conclusions}

The WRS is a promising measure for use across geo-cultural contexts to inform mental health policies, and to foster dialogue and accountability among stakeholders about roles and responsibilities. It can help researchers study stakeholders' views about responsibilities, and how these are shaped by and shape sociocultural contexts and mental healthcare systems. 


\section{Background}

Persons with mental health problems have multiple support needs which are often inadequately met (1, 2). Their needs tend to pertain to, inter alia, housing, employment, education, treatment, and emotional and financial support $(1,2)$. Responsibility for meeting these needs is generally assumed by a variety of stakeholders, particularly patients, their families or caregivers, and governments. While services and treatment providers also play a role in mental health needs provision, it falls often to patients and families to access services and to cover their costs fully or partially, depending on the nature of the healthcare system. Moreover, in all countries, governmental policy and funding decisions shape the larger context of needs provision, i.e., how mental health services are funded, organized and provided. Despite this landscape, little is known about how various stakeholders think about responsibility for fulfilling these support needs, including how they believe such responsibility should be apportioned.

Globally, there is a great discrepancy between countries in terms of government support for treatment, housing, employment, education, and income for persons with mental disorders $(3,4)$. Ninety-six percent of high-income countries (HICs) report availability of such support compared with only $14 \%$ of low- and middle-income countries (LMICs) (5). Even within HIC and LMIC groups, there is wide variation in the amount of coverage provided by governments (6-8).

Historically, there has been relatively little user input into the structure, functioning, orientation or even the outcomes judged to be salient in mental health services. With the extensive endorsement of recoveryoriented frameworks of mental health services, particularly in HICs (9-11), patients have a greater say in defining their own recovery, and what role they themselves want to play in it.

Across contexts, families are also known to play critical roles in caregiving and supporting recovery, especially for serious mental illnesses such as psychosis (12-15). In some LMICs, families have always contributed to addressing various needs of persons with mental health problems, given prevailing cultural norms $(16,17)$ and the paucity of formal mental health resources $(18)$. Cultural norms and ideologies related to autonomy (19), family piety (20) and notions of duty (21) also dictate when individuals assume responsibility for their health, and when family or government involvement is expected. Family caregivers' evolving expectations of their mentally ill relative over time (22) also may shift their views of their responsibilities vis-à-vis other stakeholders.

A better understanding of the extent to which various stakeholders perceive one another as being responsible for providing for the needs of persons with mental illnesses would help clarify how mental healthcare structures and sociocultural contexts shape and are shaped by expectations in this regard(23). Perceived roles and responsibilities have considerable implications for mental health policies, funding decisions, and the design of mental health services (24), which are currently undergoing substantial reform globally through the growing early intervention and integrated youth mental health movements (25-27). Furthermore, on a day-to-day basis, each stakeholder's perception of their own and others' roles and responsibilities is also likely to affect the amount and type of support they actually extend. 
In the context of our longitudinal comparative study of 2-year prospective outcomes of first-episode psychosis (FEP) in India and Canada $(28,29)$, focus groups were conducted with patients, families, and clinicians, revealing differences in perceived stakeholder responsibilities across the two settings and between stakeholder groups. These varying perspectives on responsibility may contribute to differential outcomes across sociocultural settings.

Furthering our knowledge obtained through these qualitative studies requires a quantitative measurement of stakeholders' relative attributions of responsibility to governments, families and patients for addressing various needs of individuals with mental health problems in different settings. Currently, there are no measures available to achieve this objective. In this report, we present a newly designed measure, derived, at least partly, from our qualitative work, and report its psychometric properties. The new measure, the Whose Responsibility Scale (WRS), is a 22-item instrument in which patients, family members, and treatment providers (clinicians) assign relative responsibility to persons with mental health problems, families, and the government for various aspects of the treatment/recovery of persons with mental health problems.

\section{Methods}

\section{$\underline{\text { Research context }}$}

As part of a larger cross-cultural investigation of first-episode psychosis(28, 29), this study was carried out with patients, families and clinicians at two early intervention programs for youth with psychosis in Montreal, Canada and Chennai, India. Participants in Chennai were recruited from the first-episode psychosis clinic of the Schizophrenia Research Foundation (SCARF), a not-for-profit, non-governmental mental health organisation. In Montreal, participants were recruited from two nodes of McGill University's publicly funded Prevention and Early Intervention Program for Psychosis (PEPP)(30). The Chennai and Montreal programs are open to referrals from a wide variety of sources and offer a similar protocol of intensive, phase-specific, two-year psychosocial (assertive case management, family interventions, family psychoeducation, therapy, etc.) and medical (flexible use of low-dose antipsychotic medication) treatments provided by a multidisciplinary team of clinicians (case managers and psychiatrists) to individuals with first-episode psychosis(29). Persons treated with antipsychotic medication for more than 30 days or with IQ below 70, solely substance-induced or organic psychosis, pervasive developmental disorder, or epilepsy are excluded from each program. Concurrent substance use is not an exclusion criterion.

The study was approved by the relevant institutional ethics boards in Montreal and Chennai, and all participants gave informed consent. In the case of individuals younger than 18 years, participants provided assent and their parents/guardians provided consent.

\section{Participants}


The standardisation sample comprised of 57 patients, 60 family members, and 27 clinicians across study sites (Table 1). Patients were included if they had a first episode of either affective or non-affective psychosis as determined by the Structured Clinical Interview for DSM IV-TR for Axis I Disorders (SCID-IV; (31)), were between 16-35 years old, and were fluent in English or French in Montreal and English or Tamil in Chennai. The exclusion criteria were the same as that for the PEPP and SCARF programs. Family members were parents, spouses/ partners, or siblings of patients with FEP, and clinicians were case managers, psychiatrists, and other allied healthcare professionals (e.g., employment support specialists, psychologists, etc.) providing treatment at PEPP and SCARF.

\section{Whose Responsibility Scale: Development and Description}

The WRS was developed with multiple rounds of iterative discussion, feedback and modifications, involving clinician-scientists and mental health professionals at both sites with extensive experience in providing mental health care, including for persons with psychosis.

The WRS (Additional File 1) was modelled after an item that has been part of various rounds of the World Values Survey(32). The item is rated on a 10-point scale, where 1 indicates complete agreement with the statement on the left pole of the scale ("The government should take more responsibility to ensure that everyone is provided for"), 10 indicates complete agreement with the statement on the right pole of the scale ("People should take more responsibility to provide for themselves"), and selection of any other number in between these poles reflects one's relative weighting of the responsibility of each party. We included this item in the WRS, followed by a set of 21 similarly worded and structured items organized around seven needs of individuals with mental health problems: (1) general financial support, (2) housing support, (3) help with return to school/work, (4) help covering the costs of mental health services, (5) medication, (6) substance use treatment programs, and (7) mental health awareness-building and stigma reduction. These seven needs were selected based on previous literature (1,33-39); our clinical and program development experience; and focus group discussions on responsibilities of various stakeholders for supporting people with mental health problems, conducted with patients, families, and clinicians at PEPP and SCARF(40-42). An initial version of the scale was also shared with three patients and two family members and their feedback was used to refine the scale and its instructions.

For each of these seven needs, a set of three items each rated on a 10-point scale are presented, with the first requiring respondents to contrast the role of the government with the role of persons with mental health problems, the second contrasting the role of the government with the role of families of persons with mental health problems, and the third contrasting the role of families with the role of persons with mental health problems (see Additional File 1). Respondents are asked to consider the attribution of responsibilities for supporting persons with mental health problems generally, and not with respect to their own specific case. In total, 22 items were included in the WRS.

The WRS was translated from English into Tamil and French and back-translated using standardized procedures recommended by the WHO (43). The WRS can be filled out as a self-report or can be interviewer-administered. 


\section{WRS Scoring}

The first item of the WRS (taken directly from the World Values Survey(32)) is a stand-alone item and does not contribute to the scoring of the WRS. The remaining 21 items can be scored to arrive at three composite scores, reflecting the extent of responsibility attributed to (1) governments vis-à-vis persons with mental health problems, (2) governments vis-à-vis families, and (3) persons with mental health problems vis-à-vis families, for addressing all needs taken together.

To arrive at these three composite scores, all items comparing government and patient responsibilities are summed to derive the first composite score; all items comparing government and family responsibilities are summed to derive the second composite score; and all items comparing patient and family responsibilities are summed to derive the third composite score. Alternatively, scores on each individual item can be summed and then averaged to arrive at more easily interpretable scores between 1 and 10.

Depending on the research or policy objectives, one may in some cases need to estimate attributions of responsibility regarding specific needs. If so, similar composite scores can also be derived for each of the seven needs separately (e.g., if one is particularly interested in perceptions of responsibility for housing support, the three items corresponding to this need can be summed and averaged in the same way across participants).

\section{Procedure}

To establish its psychometric properties, the WRS was administered as a self-report by trained research assistants to all participants (patients, families, and clinicians) in English or Tamil in Chennai, and English or French in Montreal depending on participants' linguistic preference, at two time points approximately two weeks apart in order to establish its test-retest reliability. Trained research staff were available to answer questions if needed and to administer the feedback questionnaire to a subset of the participants. We examined the internal consistency of the WRS using data obtained from the first administration of the measure. Internal consistency estimates were calculated for each set of seven items that were summed to derive responsibilities attributed to government vis-à-vis persons with mental health problems, government vis-à-vis families, and families vis-à-vis persons with mental health problems.

We also examined the frequency distributions of WRS scores to see if respondents used all or part of the possible range (1-10) of item scores, by looking at whether there were scores between 1-3, 4-6, and 7-10 for each item.

To assess the questionnaire's acceptability, we created a brief, easy-to-understand feedback questionnaire. This scale includes two items that ask participants to rate the ease of comprehension and completion of the WRS on a 10-point Likert-type scale ( $1=$ very difficult to $10=$ very easy), and a third categorically-rated item (Was the WRS measure difficult to answer? - Yes/Somewhat/No). A subset of 
patients was approached to complete the feedback questionnaire (4-5 patients in each language, English and French in Montreal and English and Tamil in Chennai).

\section{Data analyses}

Data were analysed using IBM SPSS version 22. Descriptive data regarding the sample characteristics were represented as means, standard deviations (SDs) and percentages. The samples from the two sites were compared using independent samples t-tests or chi square tests, using .05 as the significance level. Test-retest reliability for patient, family and clinician groups were computed separately using intra-class correlation coefficient (ICC), with a two-way random effects model of variance and absolute agreement between scores at the two time points $\left(\mathrm{ICC}_{2,1}\right)$ and single measure estimates (44) with a $95 \%$ confidence interval. The ICCs were interpreted as recommended by Cicchetti (45): "poor" (ICC < 0.40), "fair" (0.40$0.59)$, "good" (0.60-0.74) and "excellent" (ICC >0.75). Disaggregated and combined reliability estimates were computed for Montreal and Chennai for the patient and family samples. Due to the smaller size of the clinician sample at each site, only combined reliability estimates were computed. Finally, test-retest reliabilities were assessed separately for the English, French, and Tamil versions of the WRS based on combined patient and family samples.

Similarly, internal consistency was computed for patient, family, and clinician samples, aggregated and disaggregated across sites. Internal consistency reliabilities were also assessed separately for the English, French, and Tamil versions of the WRS based on combined patient and family samples. Often, reliability estimates based on internal consistency (Cronbach's alphas) are interpreted as acceptable if $>0.70$, good if $>0.80$, and excellent if $>0.90$ (46). It has been argued that values below 0.60 are acceptable for exploratory research $(47,48)$ and that interpretation of such estimates be guided by how the scale was conceptualized rather than based on strict cut-offs $(49,50)$. In our study, it was decided a priori that the measure would be considered internally consistent if the Cronbach's alpha estimates were at least 0.60. Higher internal consistency estimates were not consistently expected as it was theorized that ratings (e.g., for government vis-à-vis persons with mental health problems) could reflect not only latent values about stakeholder responsibilities (e.g., a general belief that governments should take substantial responsibility for addressing key needs of persons with mental health problems), but also be influenced by the specific need area being rated (e.g., governments could be seen as more responsible for covering the costs of mental health services than the costs of substance use services).

\section{Results}

Patients at both sites ( $n=30$ Montreal; $n=26$ Chennai) were comparable in age (mid-twenties), years of education (12 years), and gender distribution (Table 1). The WRS was completed in French by 13 patients in Montreal and in Tamil by 18 patients in Chennai, with the remaining patients responding in English at both sites. Families at both sites ( $n=31$ Montreal; $n=28$ Chennai) differed significantly on some demographic variables. More family members in Montreal were women, were in the 51-60 age group, had greater than high school education, and were parents of patients with FEP. In Chennai, gender distribution 
was comparable for male and female family members, a sizeable minority of family members were in the 31-40 age group, one quarter of family members were spouses/partners, and three quarters had high school education. The WRS was completed in French by 17 family members in Montreal, and in Tamil by 24 family members in Chennai. Clinicians in Chennai were all case managers and predominantly women $(86 \%)$ in the 21-30 age group (73\%), compared to Montreal, where two-thirds were case-managers, gender distribution was equal, and the majority were in the 31-40 age group.

Test-retest reliability analysis (Table 2).

Table 2. Test-retest reliability based on ICC $(2,1)$, with single measureestimates for the samples

\begin{tabular}{|c|c|c|c|c|}
\hline \multicolumn{2}{|l|}{ Sample } & $\begin{array}{l}\text { Government-Patient } \\
\text { ICC }(2,1) \text {, } \\
(\mathrm{Cl} 95 \%)(\mathrm{N})^{\mathrm{a}}\end{array}$ & $\begin{array}{l}\text { Government-Family } \\
\text { ICC }(2,1) \text {, } \\
(\mathrm{Cl} 95 \%)(\mathrm{N})\end{array}$ & $\begin{array}{l}\text { Family-Patient } \\
\text { ICC }(2,1), \\
(\mathrm{Cl} 95 \%)(\mathrm{N})\end{array}$ \\
\hline \multirow[t]{2}{*}{ Patients } & \multirow[t]{2}{*}{ Total } & $0.709 *$ & 0.566 & 0.569 \\
\hline & & $(0.544,0.821)(53)$ & $(0.35,0.724)(53)$ & $(0.351,0.728)(52)$ \\
\hline \multirow[t]{2}{*}{ Montreal } & 0.741 & 0.602 & 0.44 & \\
\hline & $\begin{array}{l}(0.509,0.873) \\
(27)\end{array}$ & $(0.293,0.796)(27)$ & $(0.074,0.702)(26)$ & \\
\hline \multirow[t]{2}{*}{ Chennai } & 0.651 & 0.483 & 0.736 & \\
\hline & $\begin{array}{l}(0.365,0.826) \\
(26)\end{array}$ & $(0.142,0.726)(26)$ & $(0.498,0.872)(26)$ & \\
\hline \multirow[t]{2}{*}{ Families } & \multirow[t]{2}{*}{ Total } & \multirow{2}{*}{$\begin{array}{l}0.705(0.541,0.816) \\
(57)\end{array}$} & 0.73 & 0.79 \\
\hline & & & $(0.581,0.832)(27)$ & $(0.665,0.872)(55)$ \\
\hline \multirow[t]{2}{*}{ Montreal } & 0.838 & 0.827 & 0.757 & \\
\hline & $\begin{array}{l}(0.646,0.925) \\
(28)\end{array}$ & $(0.641,0.918)(28)$ & $(0.526,0.884)(26)$ & \\
\hline \multirow[t]{2}{*}{ Chennai } & 0.539 & 0.649 & 0.820 & \\
\hline & $\begin{array}{l}(0.228,0.752) \\
(29)\end{array}$ & $(0.376,0.818)(29)$ & $(0.653,0.911)(29)$ & \\
\hline \multirow[t]{2}{*}{ Clinicians } & Total & 0.883 & 0.924 & 0.768 \\
\hline & & $(0.759,0.945)(27)$ & $(0.935,0.966)(25)$ & $(0.541,0.891)(25)$ \\
\hline
\end{tabular}

${ }^{\text {a }}$ Ns vary due to missing data

* All correlation coefficients were statistically significant $(p<0.05)$. 
For the combined patient sample, the ICCs $(2,1)$ were 0.71 (good), 0.57 (fair), and 0.57 (fair) for total responsibility ratings assigned to government vis-à-vis persons with mental health problems, government vis-à-vis families, and families vis-à-vis persons with mental health problems, respectively. At each site, ICCs $(2,1)$ were generally in the good range for the patient samples, with two exceptions where it was lower and in the fair range.

For the combined family sample, the ICCs $(2,1)$ were 0.71 (good), 0.73 (good), and 0.79 (excellent) for total responsibility ratings assigned to government vis-à-vis persons with mental health problems, government vis-à-vis families, and families vis-à-vis persons with mental health problems, respectively. At each site, ICCs $(2,1)$ were generally in the excellent range for the family samples, with two exceptions where it was in the good or fair range.

For the combined clinician sample, the ICCs $(2,1)$ were 0.88 (excellent), 0.92 (excellent), and 0.77 (excellent) for total responsibility ratings assigned to government vis-à-vis persons with mental health problems, government vis-à-vis families and families vis-à-vis persons with mental health problems, respectively.

Table 3. Test-retest reliability based on ICC $(2,1)$, with single measureestimates for language-based groups

\begin{tabular}{|c|c|c|c|}
\hline Sample & $\begin{array}{l}\text { Government-Patient } \\
\text { ICC }(2,1) \text {, } \\
(\mathrm{Cl} 95 \%)(\mathrm{N})^{\mathrm{a}}\end{array}$ & $\begin{array}{l}\text { Government-Family } \\
\text { ICC }(2,1) \text {, } \\
(\mathrm{Cl} 95 \%)(\mathrm{N})\end{array}$ & $\begin{array}{l}\text { Family-Patient } \\
\text { ICC }(2,1) \text {, } \\
(\mathrm{Cl} 95 \%)(\mathrm{N})\end{array}$ \\
\hline $\begin{array}{l}\text { French (patient } \\
\mathrm{N}=12 \text { ) } \\
\text { (Family } \mathrm{N}=17 \text { ) }\end{array}$ & $\begin{array}{l}0.807 * \\
(0.632,0.904)(29)\end{array}$ & $\begin{array}{l}0.792 \\
(0.606,0.896)(29)\end{array}$ & $\begin{array}{l}0.820 \\
(0.637,0.915)(26)\end{array}$ \\
\hline $\begin{array}{l}\text { English (patient } \\
\mathrm{N}=23 \text { ) } \\
(\text { Family } \mathrm{N}=16 \text { ) }\end{array}$ & $\begin{array}{l}0.819 \\
(0.681,0.901)(39)\end{array}$ & $\begin{array}{l}0.707 \\
(0.506,0.835)(39)\end{array}$ & $\begin{array}{l}0.576 \\
(0.321,0.753)(39)\end{array}$ \\
\hline $\begin{array}{l}\text { Tamil } \\
\text { (patient } \mathrm{N}=18 \text { ) } \\
\text { (Family } \mathrm{N}=24 \text { ) }\end{array}$ & $\begin{array}{l}0.455 \\
(0.187,0.662)(42)\end{array}$ & $\begin{array}{l}0.541 \\
(0.285,0.725)(42)\end{array}$ & $\begin{array}{l}0.738 \\
(0.564,0.849)(42)\end{array}$ \\
\hline
\end{tabular}

a Ns vary due to missing data

*All correlation coefficients were statistically significant $(p<0.05)$.

Generally, we found excellent to good test-retest reliability for all language versions of the WRS (Table 3). The exceptions were for responsibility assigned to persons with mental health problems vis-à-vis families in the English version, and for responsibility assigned to the government vis-à-vis persons with mental 
health problems and the government vis-à-vis families in the Tamil version, where, in each case, the ICC $(2,1)$ was only in the fair range.

Internal consistency reliability analysis (Table 4).

Table 4: Internal consistency reliability estimates for patient, family and clinician samples (overall and by site)

\begin{tabular}{|c|c|c|c|c|c|}
\hline Rater & $\mathbf{N}$ & no of items & Pair & Sample & Cronbach's a \\
\hline \multirow[t]{9}{*}{ Patient } & 56 & 7 & Government-Patient & Total & 0.899 \\
\hline & 56 & 7 & Government-Family & Total & 0.878 \\
\hline & 56 & 7 & Family-Patient & Total & 0.85 \\
\hline & 30 & 7 & Government-Patient & Montreal & 0.955 \\
\hline & 30 & 7 & Government-Family & Montreal & 0.966 \\
\hline & 30 & 7 & Family-Patient & Montreal & 0.901 \\
\hline & 26 & 7 & Government-Patient & Chennai & 0.766 \\
\hline & 26 & 7 & Government-Family & Chennai & 0.628 \\
\hline & 26 & 7 & Family-Patient & Chennai & 0.744 \\
\hline \multirow[t]{9}{*}{ Family } & 59 & 7 & Government-Patient & Total & 0.897 \\
\hline & 59 & 7 & Government-Family & Total & 0.918 \\
\hline & 58 & 7 & Family-Patient & Total & 0.848 \\
\hline & 31 & 7 & Government-Patient & Montreal & 0.963 \\
\hline & 31 & 7 & Government-Family & Montreal & 0.934 \\
\hline & 30 & 7 & Family-Patient & Montreal & 0.924 \\
\hline & 28 & 7 & Government-Patient & Chennai & 0.835 \\
\hline & 28 & 7 & Government-Family & Chennai & 0.923 \\
\hline & 28 & 7 & Family-Patient & Chennai & 0.817 \\
\hline \multirow[t]{3}{*}{ Clinician } & 25 & 7 & Government-Patient & Total & 0.822 \\
\hline & 25 & 7 & Government-Family & Total & 0.793 \\
\hline & 25 & 7 & Family-Patient & Total & 0.643 \\
\hline
\end{tabular}


For the patient sample, Cronbach's alpha estimates were good for all three sets of items (governmentpersons with mental health problems, government-family, and family-persons with mental health problems) for the combined Montreal and Chennai samples; excellent for the Montreal sample; and acceptable for the Chennai sample. In the family sample, Cronbach's alphas for the three sets were between good and excellent for the combined Montreal and Chennai samples, excellent for the Montreal sample, and good to excellent for the Chennai sample. In the clinician sample, Cronbach's alphas were acceptable for the family-person with mental health problems and the government-family set of items, and good for the government-person with mental health problems set of items. With one exception (which was acceptable), internal consistency estimates were in the good to excellent range for the three language groups (see Table 5).

Table 5: Internal consistency-based reliability estimates across language groups

\begin{tabular}{|c|c|c|c|c|}
\hline Language & $\mathbf{N}$ & no of items & Pair & Cronbach's a \\
\hline $\begin{array}{l}\text { English } \\
\text { (Patient=25 } \\
\text { Family=17) }\end{array}$ & 42 & 7 & Government-Patient & 0.94 \\
\hline 42 & 7 & Government-Family & 0.895 & \\
\hline 42 & 7 & Family-Patient & 0.892 & \\
\hline $\begin{array}{l}\text { French } \\
\text { (Patient=13 } \\
\text { Family=18) }\end{array}$ & 31 & 7 & Government-Patient & 0.933 \\
\hline 31 & 7 & Government-Family & 0.94 & \\
\hline 30 & 7 & Family-Patient & 0.889 & \\
\hline $\begin{array}{l}\text { Tamil } \\
\text { (Patient=18 } \\
\text { Family=24) }\end{array}$ & 42 & 7 & Government-Patient & 0.808 \\
\hline 42 & 7 & Government-Family & 0.895 & \\
\hline 42 & 7 & Government-Patient & 0.797 & \\
\hline
\end{tabular}

\section{Frequency distributions of WRS scores}

With a few exceptions, scores for each individual item fell in all three ranges (1-3, 4-6 and 7-10) for all stakeholder groups (patients, families, and clinicians) irrespective of site, suggesting that as intended, the scale captured variations in individuals' views on how responsibility for meeting specific needs should be 
distributed. There were a small number of cases where the 7-10 portion of the scale was never endorsed (see Additional File 2). In all these instances, these seemed to be reflective of views held by individuals in a particular context or a particular stakeholder group, and were in the expected direction, e.g., patients in Chennai never endorsed scores between 7 and 10 (suggestive of patients being substantially more responsible than families) for addressing housing needs of individuals with mental health problems; nearly our entire sample and many young persons with and without mental health problems in India live with their families $(16,51-53)$. Similarly, clinicians at both sites never endorsed scores between 7 and 10 (i.e., suggestive of families being substantially more responsible than the government) on the item about responsibility for covering costs of mental health services, suggesting that they saw this much more as a responsibility to be fulfilled by governments.

\section{Participant feedback}

All participants completed the WRS with minimal support at both sites. Participants in Chennai $(N=10 ; 5$ each in Tamil and English) reported that the WRS was average in terms of ease of completion ( $M=$ 4.1 \pm 2.02$)$ and comprehension ( $M=4.5 \pm 1.64)$, and $8 / 10$ participants found it easy to answer. Feedback from Montreal participants ( $N=11 ; 7$ in English, 4 in French) suggested that the WRS was average in terms of ease of completion ( $M=5.54 \pm 2.94)$ and comprehension $(M=5.09 \pm 2.73)$; and $6 / 11$ participants found it easy to answer. We did not analyze separately by language given the small sample sizes, but no pattern was discernable prima facie.

\section{Discussion}

The aim of this paper was to report on the development and reliability estimates of the WRS, a self-report scale assessing stakeholders' perceptions of the relative responsibilities of the government, persons with mental health problems, and their families in addressing the support needs of persons with mental health problems. The WRS test-retest reliability was generally found to be excellent to good across the different stakeholder groups (patients, families, and clinicians), settings (Montreal and Chennai), and languages (English, French, and Tamil). Internal consistency estimates were well within the acceptable range and the tool scored in the average range overall in terms of ease of comprehension and completion. In all, the WRS performed adequately with all stakeholder groups and in the three language groups in Chennai and Montreal.

The chief strength of this measure lies in its novelty and its focus on a construct that has generally been ignored in mental healthcare: perceptions of relative responsibility for supporting various needs of individuals with mental health problems. This issue is particularly salient at a time when mental health problems are the subject of increased attention, with substantial discussion in both HIC and LMIC contexts regarding novel infrastructures, funding, and service design. We modelled scale items on an item that has been part of the World Values Survey(32) since 1990 and has proven to be sensitive to capturing differences in individuals' views about government and individual responsibilities for need provision across countries $(54,55)$. Through this tool, we extend this focus on locus of responsibility to mental 
healthcare. Taken as a whole, the tool allows the assessment of the weighing of relative (rather than absolute) judgments of responsibility apportioned to governments vis-à-vis patients, governments vis-àvis families, and families vis-à-vis patients - three key stakeholder groups in mental healthcare, irrespective of geo-cultural context. It also allows for stakeholders to hold varying views about how responsibility should be distributed based on the need area being assessed. This is important, as perceptions of responsibility may vary based on the support need in question(23). For instance, some stakeholders may generally hold governments more responsible than patients or families for covering the costs of mental health services but hold patients more responsible for covering the costs of treatment for substance use.

The WRS is a promising tool with policy, research, and clinical applications. Using tools like the WRS can help ensure that health policy development in specific settings is informed by inputs from all stakeholder groups regarding the priorities and perceived responsibilities of the state vis-à-vis other actors. Although rarely done to date, such stakeholder consultation can result in greater clarity of roles and responsibilities, strengthened participation of all stakeholders, and citizen-informed health policy (56). In global health research, the WRS can help measure attitudes about healthcare responsibilities, how they differ across contexts and stakeholder groups, what underpins these differences (e.g., healthcare structures, value systems, etc.), and how these attitudes shape the organization, delivery, and outcomes of health services. While the WRS has more appreciable applications in policymaking and research, clinically, the entire tool or selected items pertaining to particular need areas can be used to foster awareness, dialogue and understanding among patients, families, and clinicians about roles and responsibilities in the treatment context. Such discussion can promote shared understanding and decision-making, and improve patientfamily, patient-provider and provider-family relationships (57).

\section{Limitations}

Our psychometric testing focused on test-retest and internal consistency reliability, with additional evaluation of the scale's ease of use. Test-retest reliability was higher for clinicians compared to patients and families, which may have resulted from them having found the tool easier to comprehend and complete. However, because the feedback questionnaires were administered only to patients, we are limited in our ability to comment on how families and clinicians perceived the tool. While the majority of patients who completed the feedback questionnaire did not perceive the WRS to be difficult to answer, a minority (7/21 patients) did. As the original intent was for the WRS to be either self-administered or interviewer-administered, we recommend flexible use of the tool, employing an interviewer-administered modality whenever necessary and feasible. Future research employing cognitive interviewing (58) and more in-depth user consultation may be helpful in changing instructions for greater clarity and accessibility, and perhaps even in further refining the tool. Notwithstanding the value of such future research, our current efforts are a noteworthy first-ever attempt at measuring views about the relative roles of pertinent stakeholder groups in mental health care. 
We did not specifically report on the WRS's validity in this report. However, the scale derives construct and content validity from the construct of perceptions of relative responsibility being well-supported by a critical literature review(23), and the seven need dimensions assessed by the WRS being identified on the basis of previous literature $(1,33-39)$ and focus groups conducted with patients, families and clinicians across two different settings in Canada and India(40-42). Finally, we have collected WRS data from patients, families and service providers in Chennai, India and Montreal, Canada to determine whether stakeholders across the two sites differ in their perceptions of relative responsibilities, which we plan to publish in the future. If the scale detects hypothesized differences in stakeholders' perceptions across sites (e.g., all Chennai stakeholders assign more responsibility to families), this would directly support its validity. Additional investigations with specified hypotheses can be conducted (e.g., family members who assign higher levels of responsibility to families will be more involved in treatment) to establish predictive validity.

\section{Conclusion}

In conclusion, the WRS is a novel and reliable measure of values related to the central issue of who should provide for which needs in mental healthcare. It can help to operationalize the notion of shared responsibility that, though rarely measured, is widely accepted as an important organizing principle for mental health services delivery and policy. Future research should be conducted in additional LMIC and HIC settings to confirm the reliability, validity and utility of this measure in other contexts.

\section{Declarations}

\section{Ethics approval and consent to participate}

The study was approved by the relevant institutional ethics boards in Montreal and Chennai. All participants gave informed consent. In the case of individuals younger than 18 years, participants provided assent and their parents/guardians provided consent.

\section{Consent for publication}

Not applicable.

\section{Availability of data and materials}

The measure reported on in this paper, Whose Responsibility Scale, is included as Supporting Information. To use or modify the scale, please contact its primary creator at srividya.iyer@mcgill.ca. The datasets generated and/or analysed during the current study are not publicly available due to ethics approval from participants not covering public sharing but are available from the corresponding author on reasonable request.

\section{Competing interests}


The authors have no competing interests with respect to this paper.

\section{Funding}

The author(s) disclosed receipt of the following financial support for the research, authorship and/or publication of this article: This research was funded by an R-01 grant (no. 5R01MH093303- 05) and an associated supplemental grant (no. R01MH093303-04) from NIH. lyer received a salary award from the Canadian Institutes of Health Research and a salary award from the Fonds de recherche du QuébecSanté. Malla was funded by the Canada Research Chairs program and Shah by a salary award from Fonds de Recherche Quebec - Santé. The funding source had no further role in study design, data collection and analysis, writing of the report, and in the decision to submit the report for publication.

\section{Authors' contributions}

SNI, MP, HL \& GM contributed to scale design. AM, SNI, TR, MP, PR, RJ \& NS contributed to conception of the larger project that included scale development and testing. SNI, AM, TR, GM, MP \& PR contributed to data acquisition. AT conducted the analyses with inputs from SNI \& AM. SNI, AT \& MP wrote the first draft of the manuscript. All authors reviewed and provided critical inputs, and finally approved the manuscript.

\section{Acknowledgements}

We would like to thank the Montreal and SCARF patients, families and teams. Specifically, we would like to thank Drs Mangala Ramamurthy, Shivaprakash Srinivasan and T.C. Rameshkumar, and Helen Martin, Sneha Natarajan, Arthy Jayavel, Shruthi Rao and Anjhana Krishnamoorthi who contributed to service delivery and data collection at SCARF. From the Montreal team, we would like to thank Nicole Pawliuk, Kevin MacDonald, Geraldine Etienne and Emily Schorr for supporting data collection, data management and project coordination. We also thank Dr. Howard Margolese and the PEPP-MUHC program for their help with recruitment for this study.

\section{References}

1. MHCC. Changing directions, changing lives: The mental health strategy for Canada. Calgary: Mental Health Commission of Canada; 2012.

2. WHO. Mental health action plan 2013-2020. Geneva, Switzerland: World Health Organization; 2013. Report No.: Retrieved from http://apps.who.int/iris/bitstream/10665/89966/1/9789241506021_eng.pdf?ua=1.

3. Saxena S, Thornicroft G, Knapp M, Whiteford H. Resources for mental health: scarcity, inequity, and inefficiency. The Lancet. 2007;370(9590):878-89.

4. Vigo DV, Kestel D, Pendakur K, Thornicroft G, Atun R. Disease burden and government spending on mental, neurological, and substance use disorders, and self-harm: cross-sectional, ecological study of health system response in the Americas. The Lancet Public Health. 2019;4(2):e89-e96. 
5. WHO. Mental Health Atlas 2017. Geneva: World Health Oorganization; 2018. Contract No.: Licence: CC BY-NC-SA 3.0 IGO.

6. Park DS, Han J, Torabi M, Forget EL. Managing mental health: why we need to redress the balance between healthcare spending and social spending. BMC Public Health. 2020;20(1):1-8.

7. Rathod S, Pinninti N, Irfan M, Gorczynski P, Rathod P, Gega L, et al. Mental health service provision in low-and middle-income countries. Health Services Insights. 2017;10:1-7.

8. Canada. Canada Health Act: Annual Report 2019-2020. Ottawa Canada: Health Canada; 2021.

9. Farkas M, Gagne C, Anthony W, Chamberlin J. Implementing recovery oriented evidence based programs: Identifying the critical dimensions. Community Mental Health Journal. 2005;41(2):141-58.

10. Le Boutillier C, Leamy M, Bird VJ, Davidson L, Williams J, Slade M. What does recovery mean in practice? A qualitative analysis of international recovery-oriented practice guidance. Psychiatric Services. 2011;62(12):1470-6.

11. Slade M, Amering M, Farkas M, Hamilton B, O'Hagan M, Panther G, et al. Uses and abuses of recovery: implementing recovery-oriented practices in mental health systems. World Psychiatry. 2014;13(1):12-20.

12. Anderson KK, Fuhrer R, Malla AK. "There are too many steps before you get to where you need to be": Help-seeking by patients with first-episode psychosis. Journal of Mental Health. 2013;22(4):384-95.

13. Baronet A-M. Factors associated with caregiver burden in mental illness: a critical review of the research literature. Clinical Psychology Review. 1999;19(7):819-41.

14. Lavis A, Lester H, Everard L, Freemantle N, Amos T, Fowler D, et al. Layers of listening: qualitative analysis of the impact of early intervention services for first-episode psychosis on carers' experiences. The British Journal of Psychiatry. 2015;207(2):135-42.

15. McCann TV, Lubman DI, Clark E. First-time primary caregivers' experience accessing first-episode psychosis services. Early Intervention in Psychiatry. 2011;5(2):156-62.

16. Avasthi A. Preserve and strengthen family to promote mental health. Indian Journal of Psychiatry. 2010;52(2):113-26.

17. Faqurudheen $\mathrm{H}$, Mathew $\mathrm{S}$, Kumar TM. Exploring family resilience in a community mental health setup in south India. Procedia Economics and Finance. 2014;18:391-9.

18. Kakuma R, Minas H, Van Ginneken N, Dal Poz MR, Desiraju K, Morris JE, et al. Human resources for mental health care: current situation and strategies for action. The Lancet. 2011;378(9803):1654-63.

19. Hervik SEK, Thurston M. 'It's not the government's responsibility to get me out running $10 \mathrm{~km}$ four times a week'-Norwegian men's understandings of responsibility for health. Critical Public Health. 2016;26(3):333-42.

20. Fan R. Which care? Whose responsibility? And why family? A Confucian account of long-term care for the elderly. The Journal of Medicine and Philosophy. 2007;32(5):495-517.

21. Koschorke M, Padmavati R, Kumar S, Cohen A, Weiss HA, Chatterjee S, et al. Experiences of stigma and discrimination of people with schizophrenia in India. Social Science and Medicine. 
2014;123:149-59.

22. Karp DA, Watts-Roy D. Bearing responsibility: How caregivers to the mentally ill assess their obligations. Health 1999;3(4):469-91.

23. Pope MA, Malla AK, lyer SN. Who should be responsible for supporting individuals with mental health problems? A critical literature review. International Journal of Social Psychiatry. 2018;64(3):293-302.

24. Corrigan PW, Watson AC. Factors that explain how policy makers distribute resources to mental health services. Psychiatric Services. 2003;54(4):501-7.

25. Colizzi M, Lasalvia A, Ruggeri M. Prevention and early intervention in youth mental health: is it time for a multidisciplinary and trans-diagnostic model for care? International Journal of Mental Health Systems. 2020;14:1-14.

26. Hetrick SE, Bailey AP, Smith KE, Malla A, Mathias S, Singh SP, et al. Integrated (one-stop shop) youth health care: Best available evidence and future directions. Medical Journal of Australia. 2017;207(S10):S5-S18.

27. Malla A, lyer S, McGorry P, Cannon M, Coughlan H, Singh S, et al. From early intervention in psychosis to youth mental health reform: a review of the evolution and transformation of mental health services for young people. Social Psychiatry and Psychiatric Epidemiology. 2016;51(3):319-26.

28. Iyer SN, Malla A, Taksal A, Maraj A, Mohan G, Ramachandran P, et al. Context and contact: a comparison of patient and family engagement with early intervention services for psychosis in India and Canada. Psychological Medicine. 2020:1-10.

29. Malla A, lyer SN, Rangaswamy T, Ramachandran P, Mohan G, Taksal A, et al. Comparison of clinical outcomes following 2 years of treatment of first-episode psychosis in urban early intervention services in Canada and India. The British Journal of Psychiatry. 2020;217(3):514-20.

30. Iyer S, Jordan G, MacDonald K, Joober R, Malla A. Early intervention for psychosis: a Canadian perspective. The Journal of Nervous and Mental Disease. 2015;203(5):356-64.

31. First MB, Spitzer RL, Gibbon M, Williams JB. Structured clinical interview for DSM-IV-TR axis I disorders, research version, patient edition (SCID-I/P). New York, NY, USA; 2002.

32. Inglehart R, Haerpfer C, Moreno A, Welzel C, Kizilova K, Diez-Medrano J, et al. World Values Survey: Round Six - http://www.worldvaluessurvey.org/WVS 2014 [

33. Browne G, Courtney M. Housing, social support and people with schizophrenia: A grounded theory study. Issues in Mental Health Nursing. 2005;26(3):311-26.

34. Cohen KR, Peachey D. Access to psychological services for Canadians: Getting what works to work for Canada's mental and behavioural health. Canadian Psychology/Psychologie canadienne. 2014;55(2):126-30.

35. Fossey EM, Harvey CA. Finding and sustaining employment: a qualitative meta-synthesis of mental health consumer views. Canadian Journal of Occupational Therapy. 2010;77(5):303-14.

36. Gardner DM, Baldessarini RJ, Waraich P. Modern antipsychotic drugs: a critical overview. Canadian Medical Association Journal. 2005;172(13):1703-11. 
37. Harvey C, Killackey E, Groves A, Herrman H. A place to live: Housing needs for people with psychotic disorders identified in the second Australian national survey of psychosis. Australian and New Zealand Journal of Psychiatry. 2012;46(9):840-50.

38. Killackey EJ, Jackson HJ, Gleeson J, Hickie IB, McGorry PD. Exciting career opportunity beckons! Early intervention and vocational rehabilitation in first-episode psychosis: employing cautious optimism. Australian and New Zealand Journal of Psychiatry. 2006;40(11-12):951-62.

39. Rinaldi M, Killackey E, Smith J, Shepherd G, Singh SP, Craig T. First episode psychosis and employment: a review. International Review of Psychiatry. 2010;22(2):148-62.

40. Iyer S, Loohuis H, Pope M, Rangaswamy T, Malla A. Family factors in first-episode psychosis in Chennai, India and Montreal, Canada: a mixed-method study: B27. Early Intervention in Psychiatry. 2014;8:104.

41. Iyer S, Pope M, Loohuis H, Schorr E, Rangaswamy T, Malla A. First-episode psychosis in Chennai, India and Montreal, Canada: A mixed method approach to the study of family factors across contexts. European Archives of Psychiatry and Clinical Neuroscience. 2015;265:S63.

42. Pope MA, Jordan G, Venkataraman S, Malla AK, lyer SN. "Everyone has a role": perspectives of service users with first-episode psychosis, family caregivers, treatment providers, and policymakers on responsibility for supporting individuals with mental health problems. Qualitative Health Research. 2019;29(9):1299-312.

43. WHO. Process of translation and adaptation of instruments: World Health Organization; 2019 [

44. Shrout PE, Fleiss JL. Intraclass correlations: uses in assessing rater reliability. Psychological Bulletin. 1979;86(2):420-8.

45. Cicchetti DV. Guidelines, criteria, and rules of thumb for evaluating normed and standardized assessment instruments in psychology. Psychological Assessment. 1994;6(4):284-90.

46. George D, Mallery E. SPSS for Windows step by step: A Simple Guide and Reference. 11.0 Update: Boston: Allyn \& Bacon; 2003.

47. Hair J, Black W, Babin B, Anderson R. Multivariate data analysis2010.

48. Taber KS. The use of Cronbach's alpha when developing and reporting research instruments in science education. Research in Science Education. 2018;48(6):1273-96.

49. Cho E, Kim S. Cronbach's coefficient alpha: Well known but poorly understood. Organizational Research Methods. 2015;18(2):207-30.

50. Cortina JM. What is coefficient alpha? An examination of theory and applications. Journal of Applied Psychology. 1993;78(1):98-104.

51. Chadda RK, Deb KS. Indian family systems, collectivistic society and psychotherapy. Indian Journal of Psychiatry. 2013;55(Suppl 2):S299.

52. Dommaraju P. Living Alone in India: Gender and Policies. Global Social Security Review 2019;11:509. 
53. Srinivasan TN, Thara R. At issue: Management of medication noncompliance in schizophrenia by families in India. Schizophrenia bulletin. 2002;28(3):531-5.

54. Andersen R, Curtis J. Social class, economic inequality, and the convergence of policy preferences: Evidence from 24 modern democracies. Canadian Review of Sociology/Revue canadienne de sociologie. 2015;52(3):266-88.

55. Pitlik H, Rode M. Individualistic values, institutional trust, and interventionist attitudes. WIFO Working Papers; 2016.

56. Canada H. Health Canada Policy Toolkit for Public Involvement in Decision Making. Ottawa, Canada: Minister of Public Works and Government Services Canada; 2000.

57. Wittenberg Y, Kwekkeboom R, Staaks J, Verhoeff A, de Boer A. Informal caregivers' views on the division of responsibilities between themselves and professionals: A scoping review. Health and Social Care in the Community. 2018;26(4):e460-e73.

58. Beatty PC, Willis GB. Research synthesis: The practice of cognitive interviewing. Public Opinion Quarterly. 2007;71(2):287-311.

\section{Table 1}

\section{Table 1: Sample characteristics}




\begin{tabular}{|c|c|c|c|c|c|}
\hline \multirow{2}{*}{\multicolumn{2}{|c|}{ Variable }} & $\begin{array}{l}\text { Montreal } \\
\text { M (SD) / } \\
\text { (\%) }\end{array}$ & $\begin{array}{l}\text { Chennai } \\
\text { M (SD) / } \\
\text { N (\%) }\end{array}$ & $\begin{array}{l}\text { Statistical } \\
\text { Test (df) }\end{array}$ & $\begin{array}{l}\text { p- } \\
\text { value }\end{array}$ \\
\hline & & $\mathrm{N}=30$ & $\mathrm{~N}=26$ & & \\
\hline \multicolumn{2}{|c|}{ Age at entry (years) } & $23.75(5.08)$ & $\begin{array}{l}26.23 \\
(5.34)\end{array}$ & $\begin{array}{l}t(54)= \\
1.775\end{array}$ & 0.082 \\
\hline \multirow{2}{*}{\multicolumn{2}{|c|}{$\begin{array}{l}\text { Gender N (\%) } \\
\text { Men }\end{array}$}} & & & \multirow{3}{*}{$\begin{array}{l}\chi^{2}(2)= \\
0.045\end{array}$} & \multirow[t]{3}{*}{0.832} \\
\hline & & $17(56.7)$ & $14(53.8)$ & & \\
\hline \multicolumn{2}{|l|}{$\begin{array}{l}\text { Men } \\
\text { Women } \\
\end{array}$} & $13(43.3)$ & $12(46.2)$ & & \\
\hline \multicolumn{2}{|c|}{ Education (years) } & $12.16(2.29)$ & $\begin{array}{l}12.46 \\
(3.99)\end{array}$ & $\begin{array}{l}\mathrm{t} \\
(38.593) \\
=0.332 \\
\end{array}$ & 0.742 \\
\hline \multicolumn{2}{|c|}{ Family Sample } & $\mathrm{N}=29^{\mathrm{b}}$ & $\mathrm{N}=28$ & & \\
\hline \multirow{5}{*}{$\begin{array}{l}\text { Age range in } \\
\text { years }\end{array}$} & $21-30$ & $3(10.3)$ & $3(10.7)$ & \multirow{5}{*}{$\begin{array}{l}\chi^{2}(4)= \\
14.177\end{array}$} & \multirow[t]{5}{*}{0.007} \\
\hline & $31-40$ & $1(3.4)$ & $11(39.3)$ & & \\
\hline & $41-50$ & $5(17.2)$ & $2(7.1)$ & & \\
\hline & $51-60$ & $16(55.2)$ & $12(42.9)$ & & \\
\hline & $61-70$ & $4(13.8)$ & 0 & & \\
\hline \multirow{2}{*}{ Gender } & Men & $5(17.2)$ & $13(46.4)$ & \multirow{2}{*}{$\begin{array}{l}\chi^{2}(1)= \\
5.617\end{array}$} & \multirow[t]{2}{*}{0.018} \\
\hline & Women & $24(82.8)$ & $15(53.6)$ & & \\
\hline \multirow{6}{*}{ Education } & Less than high school & $1(3.4)$ & $1(3.6)$ & \multirow{6}{*}{$\begin{array}{l}\chi^{2}(5)= \\
18.966\end{array}$} & \multirow[t]{6}{*}{0.002} \\
\hline & High school & $7(24.1)$ & $21(75)$ & & \\
\hline & $\begin{array}{l}\text { College/vocational } \\
\text { degree/ Diploma }\end{array}$ & $8(27.6)$ & $1(3.6)$ & & \\
\hline & Bachelor's degree & $10(34.5)$ & $2(7.1)$ & & \\
\hline & Master's degree & $3(10.3)$ & $2(7.1)$ & & \\
\hline & Doctoral degree & 0 & $1(3.6)$ & & \\
\hline \multirow{4}{*}{$\begin{array}{l}\text { Relationship } \\
\text { with patient }\end{array}$} & Parent & $23(79.3)$ & $14(50)$ & \multirow{4}{*}{$\begin{array}{l}\chi^{2}(3)= \\
9.908\end{array}$} & \multirow[t]{4}{*}{0.019} \\
\hline & Spouse/ Partner & 0 & $7(25)$ & & \\
\hline & Sibling & $4(13.8)$ & $6(21.4)$ & & \\
\hline & Other & $2(6.9)$ & $1(3.6)$ & & \\
\hline \multicolumn{2}{|l|}{$\begin{array}{l}\text { Clinician } \\
\text { sample }\end{array}$} & $\mathrm{N}=12$ & $\mathrm{~N}=15$ & & \\
\hline \multirow[t]{4}{*}{ Age } & $21-30$ & $1(8.3)$ & $11(73.3)$ & \multirow{4}{*}{$\begin{array}{l}\chi^{2}(3)= \\
14.288\end{array}$} & \multirow[t]{4}{*}{0.003} \\
\hline & $31-40$ & $7(58.3)$ & $2(13.3)$ & & \\
\hline & $41-50$ & $1(8.3)$ & $2(13.3)$ & & \\
\hline & $51-60$ & $3(25)$ & 0 & & \\
\hline \multirow[t]{2}{*}{ Gender } & Men & $6(50)$ & $2(13.3)$ & \multirow{2}{*}{$\begin{array}{l}\chi^{2}(1)= \\
4.299\end{array}$} & \multirow[t]{2}{*}{0.038} \\
\hline & Women & $6(50)$ & $13(86.7)$ & & \\
\hline \multirow[t]{3}{*}{ Profession } & Case-Manager & $8(66.7)$ & $15(100)$ & $\chi^{2}(2)=$ & 0.053 \\
\hline & Physician/Psychiatrist & $2(16.7)$ & 0 & 5.87 & \\
\hline & $\begin{array}{l}\text { Other Allied } \\
\text { Healthcare } \\
\text { Professionals }\end{array}$ & $2(16.7)$ & 0 & & \\
\hline
\end{tabular}

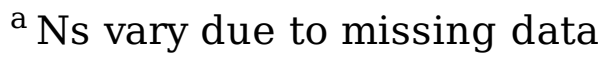


$\mathrm{b}$ Though number of family participants was 31 at Montreal, demographic data were available for only 29 of these participants

\section{Supplementary Files}

This is a list of supplementary files associated with this preprint. Click to download.

- AdditionalFile1.docx

- AdditionalFile2.docx 